\title{
LAYANAN ANAK USIA DINI/PRASEKOLAH DENGAN “FULL DAY CARE” DI TAMAN PENITIPAN ANAK
}

\author{
Oleh: \\ Yulinda Hamdiani, Dessy Hasanah Siti A, \& Gigin Ginanjar Kamil Basar \\ email: yulindahamdiani@gmail.com
}

\begin{abstract}
Abstrak. Anak usia dini merupakan fase kehidupan manusia yang menentukan perkembangan . perkembangan anak ditunjang dengan bagaimana pemenuhan kebutuhan dan dengan cara apa pemenuhan kebutuhan tersebut dilakukan. Bagi orang tua yang bekerja, upaya pemenuhan kebutuhan anak tidak dilakukan secara optimal. Untuk itu terdapat alternatif bagi orang tua atau ibu yang bekerja agar dapat tetap memberikan hak-hak anak dan sebagai upaya terhindar dari penelantaran pada anak. Penitipan Anak menjadi solusi bagi mereka yang berkarir. Lembaga pelayanan sosial dalam bidang kesejahteraan anak ini sebagai peran orang tua sementara bagi anak. Tipe pelayanan berdasarkan waktu salah satunya full day care, dimana anak selama seharian penuh dititipkan di TPA hingga orangtua atua ibu selesai bekerja. Penelitian ini bertujuan untuk menggambarkan pelaksanaan full day care yang ada di salah satu TPA yang ada di Kabupaten Bandung. Bagaimana pelaksanaan full day care dari segi program perawatan/pengasuhan, pendidikan, gizi dan kesehatan, sumber daya manusia, dan hambatannya. Subjek penelitian ini adalah Lembaga Taman Penitipan Anak Subjek diambil dengan teknik jenis purposive sampling atau sampel bertujuan karena diharapkan memperoleh informan yang mengetahui mengenai objek penelitian. Metode penelitian ini adalah penelitian deskriptif kualititatif Analisis data yang digunakan adalah analisis analisis data dilakukan dengan menggunakan reduksi data, penyajian data, dan verifikasi serta triangulasi.. Hasil analisis dengan studi pustaka menunjukkan bahwa pelaksanaan system full day harus berdasarkan pada pedoman teknis penyelenggaraan taman penitipan anak. Dimana semua program dan kegiatan berbasiskan pada pemenuhan hak-hak anak dan minat anak dan atas pertimbangan kebutuhan di fase perkembangan.
\end{abstract}

Kata kunci: Anak usia dini, Taman Penitipan Anak, Full Day Care

Abstract. PreSchool children is a decisive phase of the development of human life. child development is supported with how to meet the needs of and in what manner the fulfillment of these needs do. For parents who work, addressing the needs of children are not performed optimally. For that there is an alternative for parents or mothers working in order to keep providing children's rights and as an attempt to avoid the neglect of children. Child care centers is a solution for those who are planning a career. Social service agencies in the child care centers as the role of parents as for children. Type of service based on the time one of them Ful Day Care, where children for a full day is deposited in the landfill until Atua mother's parents finish work. This study aims to describe the implementation of full day care in one of the existing landfill in Bandung regency. How the implementation of full day care program in terms of treatment / care, education, nutrition and health, human resources, and constraints. , Subjects of this study is the child care centers taken subject to the kind of purposive 
sampling techniques or expected to obtain a sample intended for informants who know about the object of research. This research method is a descriptive study used qualitative data analysis is the analysis of the data analysis done using data reduction, data presentation, and verification and triangulation. The results of the analysis of the literature shows that the implementation of the system should be based on a full day of technical guidelines for the organization of day care centers, In which all programs and activities based on the fulfillment of children's rights and interests of children and on the consideration of the needs in the development phase.

\section{Keyword: PreSchool Children, Child Care Centre, Full Day Care}

\section{PENDAHULUAN}

Dewasa ini, telah terjadinya perubahan sosial yang ada di masyarakat yang berupa nilai-nilai sosial, norma-norma sosial, pola-pola perilaku organisasi, interaksi sosial dan lainya. Hal tersebut dipengaruhi dengan semakin berkembangnya zaman yang mengharuskan individu atau masyarakat menyesuaikan perubahan yang ada.

Sebagaimana perubahan sosial yang berupa nilai mengenai orang tua yang memiliki anak yang menggambarkan ibu dan keluarga sebagai peran sentral dalam masalah pengasuhan dan pendidikan pada anak. Kini, fungsi orang tua atau ibu dapat digantikan sementara melalui peran lembaga pelayanan yang ada di masyarakat. Dengan asumsi bagaimana pun orang tua yang bekerja dan memiliki anak usia dini harus tetap memberikan pelayanan, pengasuhan dan memberikan pendidikan demi tumbuh kembang anaknya.

Data statistik menunjukan bahwa pada tahun 2013 di Indonesia terdapat 121,19 juta orang angkatan kerja, yang bekerja sebesar 114,02 juta orang (Sakernas, BPS: 2013). Jumlah angkatan kerja tahun 2010 di Kota Bandung mencapai 1.096 .879 orang. Sementara yang sudah bekerja sebanyak 953.931 orang. (http://bandung.bisnis.com/read/20110717/3/6 7334/penyerapan-tenaga-kerja-di-bandungterus-turun).

Berdasarkan data tersebut diantara angkatan kerja dan yang sudah bekerja diantaranya adalah wanita. Fenomena ibu bekerja merupakan fenomena yang sudah tidak asing lagi. Ibu yang merupakan bagian dari keluarga yang memegang peran sentral dengan anak, terpaksa menghilangkan sementara waktu intensitas kebersamaannya bersama anak. Sehingga fungsi orang tua tidak terlaksana sepenuhnya. Brinet, Freud, dan Watson dalam (Nuryanti, 2008: 4) mengemukakan bahwa pola asuh orang tua menjadi faktor yang menentukan perkembangan anak.

Berdasarkan pernyataan ahli mengenai hal tersebut dapat diberikan kesimpulan apabila kedua orang tua dalam keadaan bekerja, maka fungsi pelayanan, pengasuhan dan pendidikan anak berkurang. Oleh karena itu, ketika fungsi orang tua tidak terlaksana sepenuhnya, dikhawatirkan anak akan tidak akan tumbuh kembang secara optimal. Kondisi ini yang berdampak pada kondisi tumbuh kembang anak. Hal tersebut didukung oleh pernyataan ahli lain yang mengemukakan bahwa:

"Anak ditinggalkan oleh ibu, ayah, atau orang tuanya berdampak pada faktor psikologis. Ketika anak anak-anak dititipkan dalam suatu institusionalia ( rumah sakit, rumah yatim piatu, yayasan perawatan bayi, dan lain-lain) mereka kurang mendapatkan perawatan jasmaniah dan cinta kasih. Anak-anak tersebut mengalami innanitie psikis (kehampaan psikis, kering dari perasaan), sehingga mengakibatkan retardasi/keterlambatan pertumbuhan pada fungsi jasmaniah. Juga terdapat hambatan fungsi rohaniah, terutama pada perkembangan intelegensi dan emosi." (Kartono, 2007:20) 
Pada dasanya anak usia dini merupakan anak yang sedang mengalami masa tumbuh kembang. Sebagaimana yang dikemukakan oleh Mansur (2005: 88):

"Anak usia dini adalah kelompok anak yang berada dalam proses pertumbuhan dan perkembangan yang bersifat unik. Mereka memiliki pola pertumbuhan dan perkembangan yang khusus sesuai dengan tingkat pertumbuhan dan perkembangannya." (dalam Astri, 2012: 8)

kemudian pada anak usia dini, merupakan masa emas atau golden age, karena anak mengalami pertumbuhan dan perkembangan yang sangat pesat dan tidak tergantikan pada masa mendatang. Menurut berbagai penelitian di bidang neurologi terbukti bahwa 50\% kecerdasan anak terbentuk dalam kurun waktu 4 tahun pertama. Setelah anak berusia 8 tahun perkembangan otaknya mencapai $80 \%$ dan pada usia 18 tahun mencapai $100 \%$. (Slamet Suyanto, 2005: 6 dalam Astri, 2012: 8)

Peran ibu atau orang tua dalam keluarga merupakan penting dalam upaya perkembangan anak. Karena berkaitan dengan pemenuhan hak-hak dasar anak yang meliputi hak untuk hidup mendapatkan kasih sayang,, cinta , pengertian, hak anak untuk mendapatkan gizi dan perawatan kesahatan dan hak untuk mendapat kesempatan bermain dan berkreasi.

Untuk itu diperlukan upaya dalam meminimalisir tidak terpenuhinya kebutuhan anak usia dini. Diperlukan pengasuhan dan pendidikan yang sesuai untuk anak usia dini hal ini berkaitan dengan peran pengganti orang tua sementara yang dilakukan oleh lembaga pelayanan yang ada di masyarakat. Fenomena yang terjadi seringkali orang tua mengabaikan bagaimana pendidikan dan pengasuhan yang seharusnya diterapkan pada anak usia dini. Karena jika di masa tersebut anak tidak menerima apa yang seharusnya di dapat, di kemudian hari akan berdampak pada perkembangan anak.

Berdasarkan Undang-Undang No. 20 Tahun 2003 Pasal 28 ayat (4) menyebutkan bahwa pendidikan anak usia dini pada jalur pendidikan non formal berbentuk kelompok bermain (KB), Taman Penitipan Anak (TPA), atau bentuk lain yang sederajat.

Lembaga pelayanan sosial yang ada di masyarakat berupa tempat penitipan anak menjadi alternatif masyarakat agar anak tetap mendapatkan pengasuhan dan pendidikan melalui pemeliharaan untuk masa tumbuh kembangnya. Lembaga pelayanan di bidang anak dengan taman penitipan anak (tpa) bersifat preventif dalam menghadapi ketelantaran melalui asuhan, perawatan, pendidikan dan bimbingan anak usia dini. Sebagaimana dikemukakan oleh Perserikatan Bangsa-Bangsa (1990), yaitu :

Daycare adalah sarana pengasuhan anak dalam kelompok, biasanya dilaksanakan pada saat jam kerja. daycare merupakan upaya yang terorganisasi untuk mengasuh anak-anak di luar rumah mereka selama beberapa jam dalam satu hari bilamana asuhan orang tua kurang dapat dilaksanakan secara lengkap. dalam hal ini, pengertian daycare hanya sebagai pelengkap terhadap asuhan orang tua dan bukan sebgai pengganti asuhan orangtua . (Patmonodewo, 2003 : 77)

Salah satu lembaga pelayanan sosial yang bergerak di bidang anak usia dini yaitu Tempat Penitipan Anak Ad-Diroyah , Mekar Biru, Kota Bandung. Sebanyak 30 anak dititipkan orang tuanya yang bekerja di taman penitipan anak mulai dari usia 0 tahun hingga 6 tahun.

Hadirnya lembaga pelayanan sosial bergerak pada bidang kesejahteraan anak seperti Taman Penitipan Anak (TPA) yang menerapkan pendidikan dan pengasuhan anak usia dini melalui layanan perlu diperhatikan pelaksanaannya, karena berkaitan dengan kesejahteraan anak. Dikemukakan oleh Diana E. Papalia, dalam bukunya Human Development (2007), adalah : 
"Jenis pengasuhan di luar sekolah oleh anggota keluarga lain, baby sitter, sekolah penuh kegiatan ekstrakulikuler berpengaruh pada kesejahteraan anak". (dalam Nuryanti, 2008: 65)

Salah satu jenis pelayanan TPA adalah jenis sistem full day, dimana jenis layanan yang memberikan layanan jasa penitipan anak dengan waktu penuh. Melihat dari rentang waktu lamanya anak dititipkan, maka pelayanan lembaga sosial dalam bentuk Taman Penitipan Anak dengan sistem full day harus sesuai dengan kebutuhan yang anak usia dini yang meliputi peningkatan gizi, pengembangan intelektual, emosional dan sosial. Selain itu, layanan proses pelaksanaan program, sarana prasarana yang ada, kualitas sumber daya manusianya, dan pengaruh layanan terhadap perkembangan fisik, kognisi, emosional dan emosi perlu dijabarkan secara jelas. Oleh karena itu , perlu dikaji apakah layanan anak usia dini di TPA dengan sistem full day memenuhi kebutuhan keluarga dalam rangka membantu orang tua/keluarga dalam memantapkan fungsi keluarga dan fungsi lembaga sebagai sesuai dengan peraturan pemerintah serta sebagai wujud usaha kesejahteraan anak yang merupakan tanggung jawab sosial lembaga.

Penelitian sebelumnya dilakukan oleh Ratna Pangastuti ( 2011) dengan judul penelitian Studi Analisis Implementasi Full Day di TPA Beringharjo Kota Yogyakarta, TPA Pelangi Indonesia dan TPA Laboratorium PAUD UGM Kabupaten Sleman, dan TPA Jabal Rahmah Kabupaten Bantul. dengan hasil penelitian implementasi full day yang ada di TPA sama dan sesuai dengan pedoman pemerintah, namun perbedaan hanya terpetak dari program-program yang ditawarkan didalamnya sebagai ciri khas dan keunggulan masing-masing lembaga, tujuan dari program memberikan pengalaman langsung dan stimulasi anak sejak dini. Faktor penghambat dan pendukung TPA rata-rata terletak pada orang tua siswa. Responibilitas orang tua yang bagus pada kebutuhan anak merupakan faktor pendukung. Efektivitas program full day di TPA tidak semua TPA mengefektifkannya.

Berdasarkan penelitian sebelumnya, peneliti bermaksud meneliti dengan berfokus pada layanan sistem full day yang diberikan oleh taman penitipan anak usia dini yang ada di salah satu Kota Bandung, yakni Taman Penitipan Anak Ad- Diroyah.

Subjek penelitian dalam penelitian ini yaitu taman penitipan anak. Dipilihnya subjek penelitian dimana merupakan lembaga pelayanan sosial yang bergerak di bidang kesejahteraan anak usia dini yang melakukan layanan yang ternasuk didalamnya meliputi layanan program pengasuhan, kesehatan yang dilakukan lembaga dikarenakan anak ditinggal beberapa waktu oleh orang tua atau ibunya yang bekerja.

Objek penelitian dalam penelitian difokuskan pada penjabaran menganai layanan sistem ful day yang diberikan oleh TPA Ad-Diroyah karena berkaitan dengan aktivitas lembaga sosial yang memberikan pelayanan kepada anak-anak usia dini yang berkaitan dengan tumbuh kembangnya dan sebagai upaya yang dilakukan lembaga untuk mencapai kesejahteraan anak.

Dikaitkan dengan konsep pekerjaan sosial, pelayanan sosial merupakan merupakan jawaban terhadap tuntutan kebutuhan dan masalah yang dialami masyarakat, sebagai akibat dari perubahan masyarakat. Lembaga pelayanan sosial di bidang anak merupakan wujud upaya kesejahteraan terhadap anak. Lembaga pelayanan sosial ini bertujuan tidak hanya mendapatkan keuntungan saja, namun tujuan utamanya adalah meningkatkan kesejahteraan orang-orang yang dilayani dan meningkatkan kesejahteraan anak. Aktifitas pelayanan yang memfokuskan pada kegiatan perawatan pengganti bagi anak (day care atau foster care) yang mana membutuhkan secara penuh waktu atau paruh waktu di luar setting perawatan keluarga.

Romanyshyn 1971 dalam (Fahrudin, 2012:51) pelayanan sosial sebagai usaha-usaha dalam mengembalikan, mempertahankan dan 
meningkatkan keberfungsian sosial individuindividu, keluarga-keluarga melalui sumbersumber sosial pendukung dan proses yang meningkatkan kemampuan individu-individu dan keluarga-keluarga untuk mengatasi stress dan tuntutan-tuntutan kehidupan sosial yang normal. Hal ini sesuai dengan pengertian dan fungsi pekerjaan sosial.

Penelitian ini bermaksud untuk menggambarkan bagaimana pelayanan terhadap anak usia dini yang dilakukan oleh taman penitipan anak Ad- Diroyah di Kabupaten Bandung, yang meliputi, jenis layanan, program layanan (pengasuhan, pendidikan, gizi dan kesehatan), sarana pra sarana, kualitas sumber daya yang ada, serta hambatan dan tantangan yang dirasakan lembaga.

\section{PEMBAHASAN}

Pelayanan Taman Penitipan Anak dengan Full Day Care merupakan pelayanan yang berdasarkan waktu seharian penuh. Dengan waktu sehari penuh maka, pemenuhan kebutuhan anak digantikan sementara oleh lembaga oleh karena itu pelaksanaan Full day care harus memperhatikan kebutuhan anak, minat anak dan perkembangan pada anak.

William Stern dengan hukum konvergensi (kerjasama) mengemukakan bahwa setiap perkembangan anak faktor hereditas atau endogen dan faktor lingkungan atau eksogen/sosial itu harus saling bekerjasama. Kedua-duanya saling teribat dan saling mempengaruhi yang melibatkan pembawaanya pada proses perkembangan anak.

"Perkembangan yang sehat akan berlangsung, jika kombinasi dari fasilitas yang diberikan oleh lingkungan dan potensialitas kodrati anak bisa mendorong berfungsinya segenap kemampuan anak. Dan kondisi sosial menjadi sangat tidak sehat, apabila pengaruh lingkungan sifatmya merusak, bahkan melumpuhkan psiko-fisik anak.'(dalam Kartono, 2007:44-45)
Menurut Direktorat Pendidikan Anak Usia Dini, Kementrian Pendidikan dan Kebudayaan RI (2011) Dasar Filsafat Keberadaan TPA untuk mendukung mewujudkan anak usia dini yang berkualitas, maju, mandiri, demokrasi dan berprestasi maka dapat dirumuskan menjadi:

\section{Tempa}

Mewujudkan kualitas fisik anak usia dini melalui upaya pemeliharaan kesehatan, peningkatan mutu gizi, olahraga yang teratur, serta aktivitas jasmani sehingga anak memiliki fisik kuat, lincah daya tahan dan disiplin tinggi.

2. Asah

Member dukungan kepada anak untuk dapat belajar melalui bermain agar memiliki pengalaman yang beruna dalam mengembangkan seluruh potensinya. Kegiatan main yang bermakna, menarik, dan merangsang imajinasi, kreativitas anak untuk melakukan, mengeksplorasi, memanipulasi dan menemukan inovasi sesuai dengan minat dan gaya belajar anak.

3. Asih

merupakan penjaminan pemenuhan kubutuhan anak untuk mendapatkan perlindungan dari pengaruh yang dapat merugikan pertumbuhan dan perkembangan. Misalnya perlakuan kasar, penganiayaan fisik, mental dan psikologis.

4. Asuh

Melalui pembiasaan yang dilakukan secara konsisten untuk membentuk perilaku dan kualitas kepribadian dan jati diri anak dalam hal :

a. Integritas iman dan takwa;

b. Patriotism, nasionalisme, dan kepeloporan;

c. Rasa tanggung jawab, jiwa ksatria, dan sportivitas

d. Jiwa kebersamaa, demokratis, dan tahan uji; 
e. Jiwa tanggap (pengguasaan ilmu pengetahuan, dan teknologi) daya kritis dan idealisme;

f. Optimis dan keberanian mengambil resiko;jiwa kewirausahaan, kreatif dan professional.

Tahun Internasioanal Anak yang disponsori oleh badan Internasional, yaitu Perserikatan Bangsa-Bangsa, pada Tahun 1979 membantu mengarahkan perhatian kepada hak-hak anak. Deklarasi PBB dalam (Patmonodewo, 1995: 51) mengemukakan hak anak yang meliputi: Hak untuk memperoleh kasih sayang, cinta dan pengertian, mendapatkan gizi dan perawatan kesahatan, mendapat kesempatan bermain dan berkreasi, mempunyai nama kebangsaan, mendapat perawatan khusus bila cacat, untuk belajar agar menjadi warga negara yang berharga, Hak untuk hidup dalam kedamaian dan persaudaraan, Semua anak mempunyai hak yang sama, tidak dibedakan dan didiskriminasikan.

Berdasarkan penjelasan hak-hak anak tersebut, maka lembaga penyelenggara kesejahteraan anak harus dapat melaksananak kegiatan yang berbasis pemenuhan hak anak dan tumbuh kembang anak. Pengertian Tempat Penitipan Anak (TPA) menurut Departemen Sosial Republik Indonesia dalam rapat koordinasi "Usaha Kesejahteraan Anak" adalah sebagai berikut:

"Lembaga sosial yang memberikan pelayanan kepada anak-anak balita yang dikhawatirkan akan mengalami hambatan daam pertumbuhannya, karena ditinggalkan orang tua atau ibunya bekerja. Pelayanan ini diberikan dalam bentuk peningkatan gizi, pengembangan intelektual, emosional dan sosial. "(dalam Patmonodewo, 1995: 77)

Berdasarkan penjelasan diatas maka kegiatan pelayanan yang meliputi sistem full day, adalah melaksanakan fungsi pelayanan yang sesuai dengan kebutuhan dan perkembangan anak. Dimana program-program yang ada mencakup dalam kegiatan yang menunjang perkembangan anak.
- Perawatan/pengasuhan, kegiatan ini berbasiskan pada bagaimana guru/pengasuh melakukan perawatan pada anak dari mulai anak datang hingga menjelang pulang.

- Pendidikan, kegiatan pada program ini adalah bermain. Jadi anak-anak diberikan edukasi menggunaan metode atau cara bermain.

- Gizi, pelayanan program gizi dilakukan TPA denga memberikan asupan nutrisi pada setiap makanan dan minuman yang diberikan pada Anak. Pada pagi hari, siang dan menjelang pulang.

- Kesehatan, pelayanan program kesehatan di TPA dilakuka secara berkala mengenai kondisi kesehatan anak.

- Peran pendidik sangatlah penting karena pendidik yang ada harus berdasakan standar minimal pendidik dan mempunyai kualitas yang baik.

- Sarana prasarana menjadi faktor penunjang tumbuh kembang anak. Anak bermain dan ketika anak bermain ataupun melakukan aktivitas harus memiliki fasilitas yang layak dan cukup aman bagi anak-anak.

Tantangan dan Hambatan yang dihadapi oleh TPA adalah kepercayaan orang tua. Disatu sisi menjadi hambatan karena jika orang tua tidak merasakan kepuasan dengan pelayanan di TPA, maka dapat mempengaruhi peminatan pada layanan yang menyebabkan kegiatan pelayanan tidak maksimal. Hilangnya kepercayan masyarakat.

\section{SIMPULAN DAN SARAN}

Jadi pelaksanaan sistem full day care , terdiri dari program perawata/pengasuhan, program pendidikan pada anak dengan metoda bermain dan pembiasaan, program pemenuhan gizi dan kesehatan. Untuk melakukan hal tersebut diperlukan tenaga kerja atau sumber daya manusia yang mumpuni dan mengerti akan segala sesuatu yang berkaitan dengan 
kesejahteraan anak. Saran dan prasarana pada TPA harus memenuhi criteria pemenuhan hakhak anak dan pertimbangan atas perkembangan anak. Selain itu berdasarkan pada pedoman teknis penyelenggaraan lembaga kesejahteraan anak.

\section{SARAN}

\section{Bagi Orang Tua Anak}

Pengasuhan pada anak harus tetap diperhatikan dan lebih berkomunikasi dan interaksi lebih dengan anak, karena pada dasarnya keluarga lah yang paling utama dalam faktor penentu perkembanga anak.

\section{Bagi TPA}

Apabila sudah baik dari segi pelayanan, lebih dapat ditingkatkan kualitasnya baik dari segi sumber daya materil maupun manusianya.

\section{Bagi Peneliti Lain}

Peneliti selanjutnya dapat melakukan penelitian yang lebih mendalam, dengan meneliti variabel-variabel yang di dapat mempengaruhi perkembangan anak.

\section{DAFTAR PUSTAKA}

Adi, Isbandi Rukminto. 2013. Kesejahteraan Sosial (Pekerjaan Sosial, Pembangunan Sosial, dan Kajian Pembangunan). Jakarta: Rajawali Pers.

Budhi Wibhawa, Santoso T. Raharjo, Meilanny Budiarti S. 2010. DasarDasar Pekerjaan Sosial. Bandung: Widya Padjadjaran.

Bungin, Burhan. 2011. Penelitian Kualitatif Edisi Kedua. Jakarta: Putra Grafika.

Direktorat Pembinaan Pendidikan Anak Usia Dini, Direktorat Jendral Pendidikan Non Formal dan Informal. 2011. Petunjuk Teknis Penyelenggaraan
Taman Penitipan Anak. Jakarta: Kementrian Pendidikan Nasional.

Edelman Borden, Marian. 2001. Pengantar: Dr. Seto Mulyadi, Smart Start Panduan Lengkap Memilih Pendidikan Prasekolah Balita Anda. Bandung: Kaifa.

Erwina, Susy. Sospol Jurnal Sosial dan Politik. Kesejahteraan Sosial Sebagai Perubah Kondisi Fisik, Mental dan Sosial. Volume. 1 Nomor 1. Juni Desember 2013. Fakultas Ilmu Sosial dan Ilmu Politik Universitas Langlangbuana.

Hurlock, Elizabeth B. 1991. Psikologi Perkembangan Edisi Kelima. Jakarta: Erlangga.

Nancy Hall \& Peggy Schmidt. 2002. Sampai Jumpa Balitaku: Kiat-Kiat Meninggalkan Anak Saat Anda Bekerja atau Bepergian. Bandung: Mizan Media Utama.

Nuryanti, Lusi. 2008. Psikologi Anak. Jakarta: PT. Indeks.

Patmonodewo, Soemarti. 2003. Pendidikan Anak Prasekolah. Jakarta: Rineka Cipta.

Pangastuti, Ratna. 2011. Studi Analisis Implementasi Full Day di TPA Bringingharjo Kota Yogyakarta, TPA Pelangi Indonesia, dan TPA Laboraturium PAUD UGM Kabupaten Sleman dan TPA Jabal Rahmah Kabupaten Bantul. Tesis Program Pasca Sarjana Sunan Kalijaga UIN Studi Islam. Melalui http://digilib.uinsuka.ac.id/6859/1/ BAB\%20I\%20\%26\%20V.pdf [20/05/15]

Soetarso. 1988. Praktek Pekerjaan Sosial Jilid I. Bandung: Sekolah Tinggi Kesejahteraan Sosial.

Sugiyono. 2012. Metode Penelitian kuantitatif dan Kualitatif. Bandung: Alfabeta. 